\title{
Stress management - Study among the night shift workers working in hospital
}

\author{
Yashodhan Prakash Mahajan \\ HOD, Dept. of Accountancy, Brihan Maharashtra College of Commerce, Pune, Maharashtra, India \\ *Corresponding Author: Yashodhan Prakash Mahajan \\ Email: mahajan.bmcc@gmail.com
}

\begin{abstract}
"If you have management telling you, as HR, to go out there and create some dedication and commitment, then you are going to also be considered as the scapegoat if it doesn't happen as they expect. You become an easy 'fall guy' for management to go to their boards and blame for the high turnover or poor morale." Inviting the most suited employees and match his skills and interest to the job available in the company is a crucial step for the development and growth of any business.

Therefore human resource department have a close contact with senior executive to have a strategic planning. Deliberate determination is required to boost morale and productivity of an employee so that it can reduce the job turnover.

It can be only achieved if HR department successfully identify employees skills, arrange for training openings to enhance those skills and enhance employees satisfaction with their work allotment and working environments. Eventually HR Department takes an initiative to tackle the issue of Stress Management in their business organization.
\end{abstract}

Keywords: Stress, Stress management, Night shift workers, Human resource.

\section{Introduction}

Stress is a term heard so often that it's meaning is frequently distorted and its implications are taken for granted. In today's world, everybody seems to be talking about stress not only in daily conversation, but also through television, radio and newspapers. Stress is a universal feature of life and no one can live without experiencing some degree of stress. One may assume that only serious or intensive physical or mental injury can cause stress. This is not true: in fact: travelling in a crowded bus/train or even sheer joy is enough to activate the body's stress mechanism to some extent, Right from the beginning of civilization, human organism is subjected to stressful events: and it is self-evident that birth itself is stressful like other biological milestones such as crawling and walking. Infants also experience stresses although independent of their own action in which aversive or defensive coping behaviour (such as crying) are likely result. For the pre-school child, environment plays an important role in experiencing stressful events. Stressful experience may exert different effects at different events. Stressful experience may exert different effects at different ages. Almost any unanticipated happening or an anticipated event, with full of threat, causes the speeding-up of bodily processes. Any kind of excitement is also a stress, in the physiologist's sense of interpretation. The term 'stress' means different things to different people: and the layman and professional alike are familiar with it.

The term stress has been derived from technical sciences where it indicates an excessive and detrimental overloading of objects. Metals like steel have a certain strain capacity, but on exceeding certain values, a rupture or fracture occurs. The term was used in this sense in the nineteenth century: in the beginning of the twentieth century, the concept appeared in medical sciences to indicate overloading of the human body. Cannon (1935) related it to homeostatic tendencies in the body. He contributed much to the development of psychosomatic and socio-biological medicine; a lot of knowledge was accumulated about the relation between stress and the development of somatic disorders like cardiovascular diseases. Selye (1956) believed that if sympathetic nervous systems and endocrine system are activated in a certain way, for example, by extreme coldness or great excitement an individual can be said to be under stress. Extreme stimulations of a divergent nature being about a certain typical endocrine reaction pattern. Specific stimulations are not connected with specific reactions: stress can be induced by many different means. Actually, Selye was not particularly interested in the causes (stimuli); more important to him was the universal reaction pattern (General Adaptation Syndrome or GAS) occurring in characteristics phases.

\section{Objectives of the Study}

The present study has been undertaken with a view to find out various causes of stress management in night shift worker, the main objectives of the study are:

1. To find out the effectiveness of stress in night shift worker in private hospital

2. To find out which factors has strong effect on stress and which factor affect least

3. To know how stress affect the working of the hospital

4. To find the remedial measures to prevent stress

\section{Research Methodology}

Research is a process of systematic and in-depth study of search for any particular topic, Subject to collection, compilation, presentation and interpretation of relevant details or data. Research refers to a search of knowledge. It is a scientific and systematic search for pertinent information on a specific topic.

While determining the scope of study, the researcher was looking for a comprehensive dimension. Therefore selected private hospitals in Pune city was selected for 
study. There are 108 private hospitals (Population) are operating in Pune city, out of that $10 \%$ of population i.e. (10\% 108 hospitals) is 11 hospitals were selected for the study. Minimum two to three employees from each hospital are selected. They were interviewed and survey questionnaires get filled from them.

The research strategy adopted for this piece of research was based on surveys and cross sectional studies. Surveys were conducted to gather and analyze statistical data in order to know the preferences of the candidate and the expectation of the recruiters. Primary data is collected with the help of questionnaires and secondary data is collated with published literature and $\mathrm{E}$ - sources.

\section{Limitations of the Research}

The study is undertaken to find out the causes of the stress. The topic has a wide scope to study therefore the study is restricted with the following.

1. For this study, only night shift worker is taken into consideration.

2. Sample is restricted with only 30 employees.

3. The response of all the respondents may not be free from biases.

\section{Literature Review}

The word stress is derived from the Latin word 'stringi', which means, 'to be draw tight'. Stress is your body's way of responding to any kind of demand. It can be caused by both good and bad experiences. When people feel stressed by something going on around them, their bodies react by releasing chemicals into the blood. These chemicals give people more energy and strength, which can be a good thing if their stress is caused by physical danger. But this can also be a bad thing, if their stress is in response to something emotional and there is no outlet for this extra energy and strength. This class will discuss different causes of stress, how stress affects you, the difference between 'good' or 'positive' stress and 'bad' or 'negative' stress, and some common facts about how stress affects people today. ${ }^{1}$

Every human being has his own understanding of stress, because all demands of adaptability do evoke the stress phenomenon. Selye (1974) beautifully summarized the nature of stress in the following words:

"Everybody knows what stress is and yet nobody knows what it is"

1. "Stress is any condition that disturbs normal functioning." (Arnold, 1960)

2. "Stress is a non-specific response of the body to any demand." (Selye, 1974)

Stress is a feeling experienced when a person thinks that "the demands exceed the personal and social resources the individual is able to mobilize." 2 Stress is not always necessarily harmful. Hans Selye said in 1956, "stress is not necessarily something bad, it all depends on how you take it. The stress of exhilarating, creative successful work is beneficial, while that of failure, humiliation or infection is detrimental." Stress can be therefore negative, positive or neutral. Passing in an examination can be just stressful as failing. Sometime we know in advance that doing a certain thing will be stressful, but we are willing to doing that. For example, while planning a vacation to a hill station you know that it would be stressful at certain times. But you are willing to face those challenges. Although stress reaction depends on what an individual considers dangerous or threatening, people very greatly in general vulnerability to stress. If a person is marginally adjusted, the slightest frustration or pressure may be highly stressful. Lack of external supports - either personal or material - makes a given stress more sever and wakens an individual's capacity to cope with it. ${ }^{3}$

In a study of managerial stress experiences, Shukla (1990) has concluded that, it may be more accurate to look at stress as a pattern of inter-related experiences rather than as one single experience. The stress due to lack of freedom to work is as real as the experience of stress due to an interpersonal encounter. He has also conceded that pattern of stressful experiences appears to be unique to an individual or a group of individuals and it may be determined by the life-situations of the individual(s), as well as their personality. ${ }^{4}$

Magnitude of Stress: The problem of stress is a universal fact. But its magnitude alone differs from country to country. Similarly it differs from industry to industry, occupation to occupation and also according to the make-up of the work force. The problem of stress affects not only the industry but also the employees and their families. The stress take very often affects the working of worker \& service provided by the hospital.

Stress is one of the most important wide spread obstacle to working. The stress may be due to personal problems, sickness, sickness of family members, or any other reason. The stress may be due to the following reasons.

1. Office subordinates.

2. Your relationship with your colleagues.

3. Excessive work pressure.

4. To meet out deadlines.

5. Death of spouse, family member.

6. Children educational performance.

7. Lack of sleep.

8. Working overtime and holidays.

9. To give new result.

10. Not sufficient money to raise your standard of living.

Effect of Stress: Hospital work often requires coping with some of the most stressful situations found in any workplace. Hospital workers must deal with life-threatening injuries and illnesses complicated by overwork, understaffing, tight schedules, paperwork, intricate or malfunctioning equipment, complex hierarchies of authority and skills, dependent and demanding patients, and patient deaths; all of these contribute to stress. ${ }^{5}$

Health Effects: Stress has been associated with loss of appetite, ulcers, mental disorder, migraines, difficulty in sleeping, emotional instability, disruption of social and family life, and the increased use of cigarettes, alcohol, and 
drugs. Stress can also affect worker attitudes and behavior. Some frequently reported consequences of stress among hospital workers are difficulties in communicating with very ill patients, maintaining pleasant relations with coworkers, and judging the seriousness of a potential emergency. ${ }^{6}$

Physical Effects: Prolonged stress, by upsetting our body chemistry and other responses, can lead to or lower our resistance to disease and illness. Rather alarmingly, it has been estimated that $50 \%$ to $70 \%$ of all physical illness is at least partly caused by stress.

Everyone knows today the growing role of stress in heart disease and hypertension leading to sudden death, depression, anxiety, obesity, skin problems, cancer, alcoholism, infections and many immune disorders.

Psychological Effect: Other signs include indecisiveness, lack of concentration and loss of libido. Stress can strongly affect personal life. In counter-productive attempts to cope with stress, many individuals start relying on tobacco, alcohol and drugs, which further aggravate the problem.

Failing to cope with prolonged intense stress can lead to 'burnout'. Victims of burnout become exhausted (both emotionally and physically), grow cynical and develop negative attitude towards their work, other persons and life in general.

Essentially a degree of stress is an integral part of life and is usually tolerable. It becomes a problem when it starts to make an individual grim or uncomfortable. One may not at first be conscious of the danger; and may not realise what those persistent headaches and outbursts of temper are all about.

Social Effects: The live of night shift workers can also be severely affected by their work schedules. They experience more problems at home because of the limited time they spend with their children and spouses. Their lack of energy and their health problems can also make it difficult for them cope with the stress of raising a family and handling maritaldifficulties. It can also become difficult for them to develop relationships outside of work. They also miss out on other activities like taking their kids to school, volunteering and attending family gatherings.

\section{Techniques to Control Stress}

Bookshops are usually full of books on 'how to manage stress.' The most popular techniques are those which the people can use all the time and which act as a protection against the possibly damaging effects of a stressful life. Some of the techniques to manage the stress are as follows:

1. Relax in any situation.

2. Taking break from the work.

3. Do proper diet and exercise.

4. Gaining control over your work.

5. Negotiating home responsibilities.

6. Manage your time perfectly.

7. Listening to music.

8. Make better decisions during crises and conflict.

9. Adaptability to change.

10. Expect to leave inspired, looking forward to facing stress challenges.

11. Bring stress energy under control.

12. Increase your personal effectiveness.

13. Team productivity.

14. Increase job effectiveness.

15. Turn negative feelings in positive feelings.

16. Self-confidence.

17. Increase self-awareness.

\section{Analysis \& Interpretation of Data}

Researcher used questionnaire method to collect the primary data. Some sample interview is also carried out.

Table 1: Q. No 1 If, yes how many times you work in night shift in month?

\begin{tabular}{|l|c|c|c|}
\hline S. No & Respondents Opinion & No of Employees & Percentage \\
1 & 2 to 4days & 0 & $0 \%$ \\
\hline 2 & 1 week & 27 & $90 \%$ \\
\hline 3 & 2 week & 3 & $10 \%$ \\
\hline 4 & Entire month & 0 & $0 \%$ \\
\hline \multicolumn{2}{|r|}{ Total } & 30 & $100 \%$ \\
\hline
\end{tabular}

Out of total employees no one is work in 2 to 4 days in night shift, almost $90 \%$ employees are supposed to work at least 1 week from the month as night shift, $10 \%$ employees are work in 2 week out of the month in night shift.

Table 2: Q. No 2. Is working in a shift affects your stress level?

\begin{tabular}{|l|c|c|c|}
\hline S. No & Respondents Opinion & No of Employees & Percentage \\
1 & Yes & 22 & $73 \%$ \\
\hline 2 & No & 08 & $27 \%$ \\
\hline & Total & 30 & $100 \%$ \\
\hline
\end{tabular}

Out of the total sample $73 \%$ of employees agree upon the fact that the night shift effect on stress level as compare to morning and evening shift, while $27 \%$ of employees are of the opinion that night shift does not effect on their stress level. 
Table 3: Q. No 3. Do you feel that given break sufficient for you?

\begin{tabular}{|c|c|c|c|}
\hline S. No & Respondents Opinion & No of Employees & Percentage \\
\hline 1 & Yes & 9 & $30 \%$ \\
\hline 2 & No & 21 & $70 \%$ \\
\hline & Total & 30 & $100 \%$ \\
\hline
\end{tabular}

employees are dissatisfied by the break time offered to

$30 \%$ of employees are satisfied by the break time them. offered to them and most of the employees i.e. $70 \%$ of

Table 4: Q. No. 4 Does your organization provides you any facility reduced your stress?

\begin{tabular}{|l|c|c|c|}
\hline S. No & Respondents Opinion & No of Employees & Percentage \\
\hline 1 & Always & 10 & $34 \%$ \\
\hline 2 & Often & 7 & $23 \%$ \\
\hline 3 & Sometimes & 7 & $23 \%$ \\
\hline 4 & Never & 6 & $20 \%$ \\
\hline & Total & 30 & $100 \%$ \\
\hline
\end{tabular}

$34 \%$ of employees are agreed that they have always received facilities to reduce their stress; $23 \%$ of employees agreed that they have often received facilities to reduce their stress; $23 \%$ of employees agreed that they have sometimes received facilities to reduce their stress; $20 \%$ of employees' greed that they have never received any facilities to cope up with their stress.

Table 5: Q. No 5. Do you feel stress at work?

\begin{tabular}{|c|c|c|c|}
\hline S. No & Respondents Opinion & No of Employees & Percentage \\
\hline 1 & Yes & 23 & $77 \%$ \\
\hline 2 & No & 7 & $23 \%$ \\
\hline & Total & 30 & $100 \%$ \\
\hline
\end{tabular}

About total $87 \%$ employees said that they are happy with the salary getting by the employer. And 13\% employees said that they are not satisfied with the salary which they are getting for their work.

Table 6: Q. No 6. If yes, what is the reason of your stress?

\begin{tabular}{|l|c|c|c|} 
S. No & Respondents Opinion & No of Employees & Percentage \\
\hline 1 & Family Problem & 07 & $23 \%$ \\
2 & Health Problem & 05 & $17 \%$ \\
\hline 3 & Job Stress & 09 & $30 \%$ \\
\hline 4 & Children Education & 02 & $7 \%$ \\
\hline 5 & Other than above & 07 & $23 \%$ \\
\hline & Total & 30 & $100 \%$ \\
\hline
\end{tabular}

There are various reasons causes stress to employees. Due to family problem $23 \%$ of employees are in stress, $17 \%$ of employees due to personal health problem, $30 \%$ of employees due to job stress, $2 \%$ of employees remain in stress for their children education like admissions, exams and due to other school activities. Remaining $23 \%$ of employees remarked as other reasons such as selfimprovement, family functions, and other personal side business. It is evident from the above that stress caused by nature of job is highest among other possible causes of stress.

\section{Findings}

1. It can be concluded that because of the nature of work that is working in shift, always as emergency situation, few holidays etc., and people reluctant to work as it creates stress among them so people afraid of having long term career in the hospital industry.

2. All employees strongly agreed upon the things that they are supposed to work at least 1 week in a month as night shift

3. Sometimes rotations in the shifts help the employees to manage their routine life.

4. Majority employees agree upon the fact that the night shift effect on stress level as compare to morning and evening shift 
5. Majority employees do not have specific break time so they are dissatisfied with the working.

6. Majority of the employees don't get stress relief facilities or working conditions.

7. There is uncertainty in the working schedule, which hampers the routine life of an employee and causes rise in stress levels.

8. Night shift employees are not satisfied with the salary which they are getting for their work.

9. It is evident from the above that stress caused by nature of job is highest among other possible causes of stress.

10. Mostly men worker are enjoying their social life. On the contrary female workers very often enjoy social life, most of the time the work under stress.

11. Employees are of the opinion to have an improvement in the working environment of the organization.

12. Working in night shifts changes the routine of the employees which causes health problems to them.

\section{Conclusion}

The stress issue is a common datum. Magnitude of it is differs from country to country, industry to industry, occupation to occupation and also according to the make-up of the work force. The problem of stress not only affects the industry but also on health of the employees and social life of their families. The stress take very often affects the working of worker \& service provided by the hospital. It is one of the utmost significant wide spread hurdle to working environment. It hampers the working environment as well as the health of the employees. Primarily the causes of it must be identified and dealt carefully so as to maintain holistic and sustainable development of the society.

\section{References}

1. http://mtstcil.org/skills/stress-definition-1.html

2. Richard S Lazarus.

3. Selye, H. (1956). The Stress of Life, New York: McGraw Hill
4. Hasnain N., Shahnawaz, M.G.\& Shukla, V.(2001). Role stress and coping strategies in different occupational groups

5. https://www.osha.gov/SLTC/etools/hospital/hazards/stress/stre ss.html

6. http://www.divvyengagement.com/blog/bid/64089/Stress-isdrowning-your-hospital-personnel-Here-s-how-to-get-air

7. By Rahul Sharma, Sangeeta Jauhari, Vijay Singh. Stress Techniques and Management: A Review Paper.

8. An International Peer-Reviewed Journal Vol.13, 2015. ISSN 2422-8435.

9. Geeta Kumari, K. M. Pandey. In Studies on Stress Management: A Case Study of Avatar Steel Industries, Chennai, India. International Journal of Innovation Management and Technology. 2011;2(5).

10. Stress At Work Stress Management By Aljona Shchuka A Qualitative Study On The Causes Of Stress And Management Mechanisms At Volvo Trucks Ab, Umeåby Najmoddin Nekzada And Selamawit Fisseha Tekeste.

11. Neema Kumari Jadoun, Abdesh Singh Kushwah, Parmanand, Barodiya, Umesh Holani. Need of Stress Management.

12. International Journal Of Science, Technology \& Management.

13. Nirmala. R. A Study on Stress Management among the Employees of Banks.

14. An Empirical Study on Stress Management for Higher Secondary Students In Salem District Tamil Nadu By Dr.A. Jayakumar

15. M. Kotteeswari, S. Tameem. A Study With Reference To Employees Working In BPOs.

16. Bianca Cirjaliu, Anca Draghici, Alin Jitarel. A Proposal Approach for Stress Management.

How to cite this article: Mahajan Y. P. Stress management - Study among the night shift workers working in hospital. J Manag Res Anal. 2018;5(4):468-472. 